\title{
Cultivation and Improvement of Students' English Reading Ability in Higher Vocational Colleges
}

\author{
Lin Qi* \\ SICHUAN JUDICIAL AND POLICE OFFICERS PEOFESSIONAL COLLEGE, Deyang 618000, Sichuan, China. \\ E-mail: 710057220@qq.com
}

\begin{abstract}
With the effective implementation of quality education, the teaching reform is accelerating, and the cultivation of comprehensive literacy abilities of vocational college students has become the focus of teaching. Therefore, vocational English teaching pays more attention to improve students' reading ability. Based on the actual teaching practice, this article analyzes the current situation of English reading learning for vocational students and discusses countermeasures of improving students' English reading ability, hoping to give certain enlightenment on promoting the overall quality of vocational English teaching.
\end{abstract}

Keywords: Higher Vocational Colleges; English Reading Ability; Training; Improvement; Countermeasures

Foreword: English is an important basic subject in higher vocational education. Especially in today's global integration, the practical application of English is getting more frequent, and learning English is of great significance to students' future career development. For English learning, the reading ability is an important standard to measure students' overall English level. Students obtain the most intuitive information through the rich language input by reading, which can lay a solid foundation for the comprehensive ability of English listening, speaking, reading and writing. At the same time, students can improve their own comprehensive language skills to integrate English knowledge into practical applications. Therefore, teachers should deeply understand the importance of English reading, take the initiative to strengthen communication with students, understand students' confusion in English reading learning, and actively adopt reasonable teaching methods to guide students to learn, so that they can use what has been learned in future employment development.

\section{Problems in English reading of vocational college students}

Students in higher vocational colleges generally have low theoretical knowledge learning ability, and have a weak foundation in English learning. They have limited English vocabulary and grammar knowledge learned from middle school. Once they need to read a long article, they feel it is very difficult to fully understand the content of reading, which affects their reading speed. Due to the difficulties, some students dislike reading. They do not read at all or read the material halfway, which seriously affects their interest in English reading. Therefore, the accumulation of English vocabulary is very important for reading. This is one of the key points of English reading teaching. Teachers should clarify the importance of accumulating vocabulary to students and encourage them to enhance the accumulation of English vocabulary.

Secondly, since the middle school education advocates the exam-oriented model, students often take targeted learning in response to the exams. In this case, they do not have enough time to cultivate English reading interest and ability. Therefore, when entering the vocational learning stage, students have a poor foundation in English reading, and their reading volume is obviously insufficient. The reading materials they can master are basically limited to textbooks and

Copyright (C) 2020 Lin Qi

doi: $10.18282 /$ le.v9i6.1321

This is an open-access article distributed under the terms of the Creative Commons Attribution Non-Commercial License

(http://creativecommons.org/licenses/by-nc/4.0/), which permits unrestricted non-commercial use, distribution, and reproduction in any medium, provided the original work is properly cited. 
test questions. The articles they read are often short and the content is not rich enough. Students lack the English language and cultural background seriously so that it is very likely that they will encounter scenes and slang in reading that affect their understanding of the entire article. Therefore, their reading ability cannot be effectively improved.

In addition, reading habits are also very important for improving English reading ability. Some students have developed some bad reading habits in middle school. They read slowly, read with their fingers, dare not read aloud, like to read repeatedly, and they translate the content into Chinese to understand it. During the reading process, when encounter vocabulary that they don't understand, they habitually look up the dictionary, which makes them have to take a lot of time and effort to read an article. For English reading learning, these are very undesirable bad habits. Based on the essential difference between English and Chinese, there are big discrepancies in grammar, sentence structure, language and cultural background, etc. Only relying on a single word translation to understand the meaning of a sentence is easy to make misinterpreting errors. For some new and unfamiliar words, students should guess the meaning of words through the passage of paragraphs or suffixes to deepen their reading comprehension, because looking up the dictionary is a very limited method and is not conducive to active thinking. It is easy to distract reading attention, which will affect the overall reading progress and efficiency.

\section{Countermeasures to improve students' English reading ability}

As mentioned above, higher vocational students still have a lot of problems in English reading learning. As the focus of English education, English reading teaching must actively improve and enrich teaching methods to help students improve their English reading ability, which can be realized in the following ways:

\subsection{Stimulate students' interest in reading English}

The secret of success lies in interest. With interest as a guide, many things become easier. Once students are interested in reading, their enthusiasm for reading will be effectively mobilized, and their reading ability will naturally improve. Therefore, in actual English reading teaching, teachers should pay attention to stimulate students' reading interest, use modern multimedia teaching technology to create English reading situations for students, enhance the strong atmosphere of teaching, and stimulate students' interest. Teachers should use English during the whole class as long as possible to communicate with students, which can provide students an immersed English communication environment. They can also use vivid and practical English example sentences to enable students to learn in a relaxed atmosphere. At the same time, teachers need to create opportunities for students to practice the language as much as possible, so that students can learn to use English knowledge in specific tasks, such as English reading competitions, English situational conversations, singing English songs, performing English dramas, developing English games and so on. Through this type of teaching model, students can connect the knowledge they have learned to improve their performance and creativity. At the same time, teachers should make students feel the fun of learning English to generate greater interest, therefore, to have stronger learning needs to continue to invest in learning positively. In addition, teachers can often tell students about Western language and cultural knowledge, English jokes and foreign anecdotes, etc., which is also conducive to inspiring students' interest, triggering students' reading motivation, and promoting students' continuous improvement in English reading.

\subsection{Increase students' English vocabulary}

The improvement of English reading ability can not be achieved overnight. There are many factors that affect reading ability, such as reading skills, vocabulary, understanding of Western language and cultural background, and students' own mother tongue. For non-English major students, the accumulation of vocabulary is the most critical that the more vocabulary they master, the stronger their reading ability will be. Usually, the lack of certain vocabulary makes it difficult to analyze and understand an article. Therefore, in English reading teaching, teachers should encourage students to increase reading volume, accumulate more vocabularies, expand students' understanding of English vocabulary from the word formation and polysemy, and guide students to expand their learning by reading through the context, the word roots, affixes, etc. to guess the meaning of words and improve reading ability.

\subsection{Improve students' discourse analysis ability}


In English reading teaching, students' ability to master vocabulary and grammar is the prerequisite for reading, and the understanding of words and sentences is the basis of reading. The improvement of reading ability depends on students' discourse analysis ability. To develop students' discourse analysis ability, teachers should choose reading materials that are close to students' real life, such as political economy, character culture, social science, etc. At the same time, they should be as diverse as possible in style, such as narrative, essay, application, instructions and so on. Teachers should analyze the stylistic characteristics, combine the article title, relevant knowledge background to infer the stylistic structure, article theme, and then browse to read, using various brief descriptions, Q\&A, lists and other methods to explain the main content of the article and clarify the central idea of the article. Then, they can ask students to read in sections, understand the general meaning of each paragraph, draw out the transitional paragraphs of the article, analyze the logical order of the article, writing ideas, and permeate the language knowledge in the article. Finally, they should require students to read through the article and understand the article in depth, so that students can apply various reading methods to improve their English reading ability.

\subsection{Strengthen students' English reading speed}

To improve one's English reading ability, reading speed is also a major factor, which can help students improve reading efficiency and reading volume, thereby their reading ability will naturally improve. Therefore, increasing the students' rapid reading training is an effective teaching measure, which will have a positive effect on training students' reading ability. In addition, teachers should strengthen the training of students' reading skills, teach students to learn to skim articles, and obtain the key information content of articles through quick reading. Students are required to adopt the meanings of guessing, associating, backstepping, and analogizing articles, and learn to analyze themselves. Solve problems and exercise the comprehensive ability of English learning. In order to effectively improve the reading speed of students, teachers can randomly select materials for reading training and require students to complete reading and practice within a predetermined time. In the process of reading, students should be required to be careful and do not allow the use of dictionary tools, in order to improve their reading speed and improve reading ability.

\section{Conclusion}

All in all, improving students' English reading ability is a relatively slow process. Teachers should combine theory with practice, grasp the characteristics and existing problems of students' learning status, explore suitable and effective teaching methods, and actively cultivate students' interest in English reading. Students should accumulate a large amount of vocabulary, increase reading volume, learn language knowledge background, improve reading skills, and ultimately improve their English reading ability.

\section{References}

1. Yuan T. Ways to train students' English reading comprehension ability. Wencun Reading 2018; (22): 45.

2. Yang X. Cultivation methods of English reading literacy for vocational college students. Journal of Kaifeng Education College 2018; 38(12): 122-124.

3. Zhang W, Huo L, Li Y. Explore how to cultivate the English reading ability of vocational students. Global Market 2017; (30): 182. 